\title{
Cardiothyreosis: Risk Factors and Clinical Profile
}

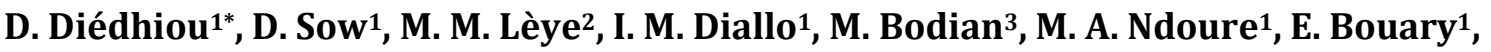 \\ M. Ndour Mbaye ${ }^{1}$, A. Sarr ${ }^{1}$, S. N. Diop ${ }^{1}$
}

1Department of Internal Medicine, Abass Ndao Hospital Center, Cheikh Anta Diop University, Dakar, Senegal
${ }^{2}$ Department of Preventive Medicine and Public Health, Cheikh Anta Diop University, Dakar, Senegal
${ }^{3}$ Cardiology Department, Aristide LeDantec Hospital Center, Cheikh Anta Diop University, Dakar, Senegal
Email: `dembadiedhiou1976@gmail.com,drdjiby@yahoo.fr, mamadou.leye@yahoo.fr, ibrahimamanediallo@hotmail.fr,
saidnorou@yahoo.fr, michelassanendour@yahoo.fr, ould_elbou@yahoo.fr, mayoumbaye@gmail.com, annasarr@orange.sn

How to cite this paper: Diédhiou, D., Sow, D., Lèye2, M.M., Diallo, I.M., Bodian, M., Ndoure, M.A., Bouary, E., Mbaye, M.N., Sarr, A. and Diop, S.N. (2017) Cardiothyreosis: Risk Factors and Clinical Profile. Open Journal of Internal Medicine, 7, 1-11. https://doi.org/10.4236/ojim.2017.71001

Received: February 11, 2017

Accepted: March 27, 2017

Published: March 30, 2017

Copyright (ㅇ 2017 by authors and Scientific Research Publishing Inc. This work is licensed under the Creative Commons Attribution International License (CC BY 4.0).

http://creativecommons.org/licenses/by/4.0/

\begin{abstract}
Introduction: The diagnosis of cardiothyreosis is based on the presence of the association of thyrotoxicosis and various cardiovascular disorders such as heart failure, coronary artery disease, rhythm or conduction disorders. Data are limited on this entity in Africa which a frequency of $10 \%$ to $33 \%$ among hyperthyroidism. We aimed to evaluate these risk factors and describe its diagnostic features in Abass Ndao Hospital Center of Dakar. Patients and Methods: It was a descriptive and analytical cross sectional study conducted from 1 January 2010 to 31 December 2014, including all cases of hyperthyroidism with cardiothyreosis. Epidemiological data, cardiovascular risk factors and characteristics of cardiothyreosis were evaluated. Results: 150 cases of cardiothyreosis were collected with a prevalence of 9.8\% among 1517 hyperthyroidism. Mean age was $42.6 \pm 9$ years and sex ratio 0.33. It was a Graves' disease in $82.2 \%$ of cases. Time limit of cardiothyreosis appearance was $27 \pm$ 41 months and cardiothyreosis was inaugural in $46.6 \%$. Electrocardiogram showed an arrhythmia (38.7\%), coronary insufficiency (8\%). On echocardiography assessment, impairment of left ventricular ejection fraction (LVEF) was found in $18.5 \%$. Of these, it was $34.7 \%$ of arrhythmia, $8.6 \%$ of coronary insufficiency and $65.2 \%$ of heart failure. Among patients with pulmonary artery hypertension (PAH) (57.3\%), there were a rhythm disorder (38\%), coronary insufficiency (5.6\%) and heart failure (78.8\%). Female gender was the only one at risk of arrhythmia $(\mathrm{p}=0.01)$ and impaired of left ventricular ejection fraction $(\mathrm{p}=0.007)$. Existence of a free $\mathrm{T} 4>50 \mathrm{pmol} / \mathrm{L}(\mathrm{p}=0.05)$ were only at risk of developing pulmonary artery hypertension. Conclusion: Cardiothyreosis is a significant complication. These discovery methods call for more early diagnosis and appropriate treatment. Female gender and severity of thyrotoxicosis seem to precipitate the clinical picture. Echocardio-
\end{abstract}


graphy remains an indispensable tool for assessing cardiac consequences.

\section{Keywords}

Cardiothyreosis, Risk Factors, Clinical Profile, Senegal

\section{Introduction}

Cardiothyreosis or thyrotoxic heart diseases are the most complications of hyperthyroidism. Its diagnosis is based on the association of thyrotoxicosis and various cardiovascular disorders such as heart failure, coronary insufficiency, rhythm or conduction disorders. Thyrotoxic heart disease is a life-threatening condition. Apart from clinical presentation, diagnostic needs electrocardiographic and/or echocardiographic evaluation [1] [2] [3]. Cardiovascular manifestations of thyrotoxicosis result from a direct effect of thyroid hormones on myocardial cell and its indirect effects resulting from interactions with the sympathetic nervous system, changes in peripheral vascular resistance, renin-angiotensin system and erythropoietin production [4]. It is an entity of the fourth decade of life and is more frequent in females. In Africa, data on cardiothyreosis are limited [5]. Prevalence between 10\% and 33\% according to the series is reported among hyperthyroidism [1] [6] [7]. Objective of this study was to describe the clinical and diagnostic features of cardiothyreosis and identifying its electrocardiographic and echocardiographic characteristics in Abass Ndao Hospital of Dakar.

\section{Patients and Methods}

It was a descriptive and analytical cross sectional study conducted in the Medical Clinic Center II and cardiology department of Abass Ndao Hospital Center in Dakar from 1 January 2010 to 31 December 2014. Medical Clinic Center II is the national reference center for the treatment of endocrine and metabolic diseases in Senegal since 1960. The study included all cases of hyperthyroidism presenting a cardiothyreosis and followed in our clinical center. Those with incomplete files (clinical or biological or cardiologycal exploration) were not included.

Hyperthyroidismis defined by an ultrasensitive TSH (TSHus) $<0.1 \mathrm{mIU} / \mathrm{l}$ and/ or an increase in thyroid hormone (free $\mathrm{T} 4$ or tetraiodothyronine and free $\mathrm{T} 3$ or tri iodothyronine) [8]. The values of TSHus and thyroid hormones were determined at fasting by immuno-radiological methods. Normal values were from 0.17 to $4.05 \mathrm{mIU} / \mathrm{L}$ for TSHus, 9 to $22 \mathrm{pmol} / \mathrm{L}$ for free T4 and 2.5 to $5.8 \mathrm{pmol} / \mathrm{L}$ for free $\mathrm{T} 3$.

All patients followed in our clinical center for hyperthyroidism were included and systematically benefited from an electrocardiogram assessment. Based on clinical and electrocardiographic data, an echocardiography evaluation was requested. The diagnosis of cardiothyreosis for all patients was confirmed based 
on clinical and paraclinical criteria (electrocardiogram and Doppler echocardiography). Electrocardiographic and echocardiography data were confirmed by an experienced cardiologist. The diagnosis of cardiothyreosis was done whether the patient present during the development of hyperthyroidism one of the following cardiac abnormalities: heart failure, coronary insufficiency or arrhythmia and/or conduction disorders [8].

Atrial flutter (AF) is a regular, continuousatrial tachycardia, with a frequency of 250 to $350 / \mathrm{min}$ and a sawtooth appearance without return to the isoelectric lineon EKG. Atrioventricular conduction rate is generally fixed to either $2 / 1$ or $4 / 1$ and rarely 6 or $8 / 1$.

Atrial fibrillation (ACFA) results in a loss of $\mathrm{P}$ waves replaced by a rapid tremor, continuous isoelectric line ( 400 to 600 per minute). The ventricular activity is usually fast and very irregular.

Supraventricular tachycardia also called "junctional tachycardia" or "Bouveret disease" coresspond to the attack of tachycardia (fast heart rate) and clinicaly manifest as palpitations with abruptstart and ending.

Pulmonary arterial hypertension $(\mathrm{PAH})$ is a rise in mean systolic pulmonary artery pressure above $35 \mathrm{mmHg}$ [9] measured by Doppler echocardiography in this study.

Dilated cardiomyopathy is a combination of a rise in diastolic diameter of the left ventricle above the threshold value of $27 \mathrm{~mm} / \mathrm{m}^{2}$ of body surface area, impaired of left ventricular ejection fraction less than the critical value of $45 \%$, with fairly diffuse thinning and hypokinesia of left ventricular walls with a normal anatomic appearance of heart valves. Mitral insufficiency is seen in approximately $30 \%-40 \%$ of cases.

The systolic ejection fraction is the ejected percentage of total blood contained in a heart chamber during a systolic contraction. It is altered if reach under $50 \%$ to $55 \%[10]$.

Files with incomplete clinical and/or paraclinical data were excluded in the final evaluation. A pre-record form is used for data collection. It covered the following:

- Epidemiological characteristics: age, sex, cardiovascular risk factors such as high blood pressure, diabetes mellitus, smoking, obesity, underlying heart disease and anemia.

- Clinical study of hyperthyroidism: delay of hyperthyroidism treatment, anthropometric parameters, and clinical signs of thyrotoxicosis, complete physical examination, and laboratory data before and/or at the time of diagnosis of thyrotoxic heart disease (free T3, free T4 and TSHus). The clinical and laboratory data were used to determine thyroid function and etiology of hyperthyroidism.

- Study of cardiothyreosis: Time limit appearance and clinical manifestations of thyrotoxic heart disease, electrocardiographic and echocardiography Doppler data were evaluated. Echocardiography encompassed assessment of cavities and walls size, valvular abnormalities, systolic ejection fraction, pulmonary arterial pressure and pericardium. The clinical and laboratory data 
allowed classifying clinical forms of cardiothyreosis as heart failure, myocardial ischemia, rhythm disorders and the combined forms.

- Epi Info 3.3.5 software was used to enter and analysis data. For descriptive analysis, the quantitative data were presented as percentage and the qualitative variables showed as mean values with standard deviation. Khi2 test was used for bivariate analysis to compare two proportions. A p value $<0.05$ was considered statistically significant with a confidence interval (CI) of 95\%. In case of correlation, the odds ratio (OR) surrounded by his interval was calculated to determine the strength of correlation.

\section{Results}

\subsection{Epidemiological Aspects and Study of Hyperthyroidism}

Among 1517 patients followed for a hyperthyroidism, 150 cases of cardiothyreosis were included. The prevalence of cardiothyreosis was $9.8 \%$ among hyperthyroidism cases. At diagnosis of cardiothyreosis, mean age of patients was $42.6 \pm$ 9 years and sex ratio $(\mathrm{M} / \mathrm{F})$ 0.33. Hyperthyroidism was present in all patients with a free $\mathrm{T} 4 \geq 50 \mathrm{pmol} / \mathrm{l}$ in $64.6 \%$. Most represented clinical signs of thyrotoxicosis (except cardiac signs) were weight loss (84\%), shiver (74.6\%), hyper sweating (72\%), thermophobia (69.3\%), asthenia (65.3\%), insomnia (62.6\%), irritability (56\%) and nervousness (53.3\%). Thinness was found in $24.6 \%$. An anemia was associated with cardiothyreosis in $24 \%$ of cases with a meanrate of hemoglobin in $9.8 \pm 1.7 \mathrm{~g} / \mathrm{dl}$. The Table 1 shows the epidemiological profile of patient.

\subsection{Study of Cardiothyreosis Feature}

\subsubsection{Clinical Data}

The mean duration from the time of hyperthyroidism diagnosis to the onset of

Table 1. Epidemiological characteristics of subjects followed for cardiothyreosis.

\begin{tabular}{cc}
\hline Epidemiological characteristics of subjects $(\mathbf{n}=\mathbf{1 5 0})$ \\
\hline Women & $112(74.6 \%)$ \\
Age $<30$ years & $33(22 \%)$ \\
Age [30 to 59 years] & $94(62.6 \%)$ \\
Age $>60$ years & $23(15.3 \%)$ \\
High blood pressure & $47(31.3 \%)$ \\
Obesity and overweight & $36(24 \%)$ \\
Diabetes mellitus & $10(6.6 \%)$ \\
Active smoking & $5(3.3 \%)$ \\
Underlying heart disease & $15(10 \%)$ \\
Anemia & $36(24 \%)$ \\
Graves' disease & $123(82 \%)$ \\
Toxic nodular goiter & $27(18 \%)$ \\
Mean body mass index & $22.3 \pm 5 \mathrm{~kg} / \mathrm{m}^{2}$ \\
Mean free T4 & $77.2 \pm 50 \mathrm{pmol} / 1$ \\
\hline
\end{tabular}


thyrotoxic heart disease was $27 \pm 40$ months. This period was 1 to 36 months in $29.3 \%$, and more than 3 years in $24 \%$ of cases. Thyrotoxic heart disease was inaugural in 70 cases $(46.6 \%)$. Clinically the average heart rate was $105 \pm 19$ beats/mn. Others clinical signs of cardiothyreosis were showed in Table 2.

\subsubsection{Electrocardiographic Findings (Table 3)}

Electrocardiogram showed a cavity hypertrophy in $62 \%$. Arrhythmia or conducting disorders was found in 58 cases (38.7\%). Among the 58 subjects with latter disorders, mean age was $44 \pm 15$ years, sex ratio 0.61 , time limit onset of thyrotoxic heart disease $34.8 \pm 48$ month and mean free T4 value $74.6 \pm 38$ pmol/l. Diabetes mellitus was detected in $8.7 \%, 26.3 \%$ showed hypertension and 84.2\% among them had Graves' disease. Occurrence of Arrhythmias and female gender was statistically linked $(\mathrm{p}=0.01)$. Moreover, there was no statistically significant association between other patient's factors and the occurrence of arrhythmias ( $p>0.05)$. In 12 patients (8\%), electrocardiographic findings were suggestive of coronary insufficiency. Their mean age, sex ratio, time limit onset of thyrotoxic heart disease and mean free T4 were respectively $53 \pm 8$ years, 0.2 , $39 \pm 27$ months and $68.3 \pm 38 \mathrm{pmol} / \mathrm{l}$. It was about $8.3 \%$ diabetic, $58.3 \%$ hypertension and $83.3 \%$ Graves' disease. Only 2 patients had concomitant coronary insufficiency and atrial fibrillation.

\subsubsection{Doppler Echocardiography Findings (Table 4)}

Only 124 of 150 cases of cardiothyreosis underwent echocardiography. Among them, $58 \%$ showed heart chamber enlargement, $8 \%$ heart walls hypertrophy and

Table 2. Distribution of clinical manifestations depending on age and time limit to onset.

\begin{tabular}{cccc}
\hline Cardiothyreosis clinical data & $\begin{array}{c}\text { All patients } \\
(\mathbf{n}=\mathbf{1 5 0})\end{array}$ & $\begin{array}{c}\text { Cardiothyreosis } \\
\text { inaugural (n= 70) }\end{array}$ & $\begin{array}{c}\text { Age }>\text { 50 years } \\
(\mathbf{n}=\mathbf{4 9})\end{array}$ \\
\hline Palpitation & $97.3 \%$ & $98 \%$ & $100 \%$ \\
Tachycardia & $64.6 \%$ & $64.7 \%$ & $52 \%$ \\
Heart dyspnea stages I and II & $21.3 \%$ & $24.2 \%$ & $22.4 \%$ \\
Heart dyspnea stage III & $64.6 \%$ & $58.5 \%$ & $63.2 \%$ \\
Heart dyspnea stage IV & $14 \%$ & $17.1 \%$ & $12.2 \%$ \\
Cardiovascular excitability & $24 \%$ & $22.8 \%$ & $20.4 \%$ \\
Orthopnea & $13.3 \%$ & $17.1 \%$ & $12.2 \%$ \\
Acute pulmonary edema & $3.3 \%$ & $4.2 \%$ & $4 \%$ \\
Edema of lower limbs & $66 \%$ & $61.4 \%$ & $63.2 \%$ \\
jugular vein high pressure & $70.6 \%$ & $69 \%$ & $73.4 \%$ \\
Hepatomegaly & $11.3 \%$ & $11.4 \%$ & $12.2 \%$ \\
Ascites & $2.6 \%$ & $4.2 \%$ & $0 \%$ \\
Pleural effusion & $0.6 \%$ & $0 \%$ & $2 \%$ \\
Cardiac rhythm disorders & $42.6 \%$ & $41.4 \%$ & $38.7 \%$ \\
Gallop & $8 \%$ & $7.1 \%$ & $4 \%$ \\
Heart Murmur & $22 \%$ & $24.2 \%$ & $12.2 \%$ \\
\hline
\end{tabular}


Table 3. Distribution of electrocardiographic and echocardiographic signs.

\begin{tabular}{|c|c|c|}
\hline \multicolumn{2}{|c|}{ Electrocardiographic data $(n=150)$} & \multirow{2}{*}{$\begin{array}{c}\text { Subject }>50 \text { years }(\mathrm{n}=\mathbf{4 9}) \\
22(44.8 \%)\end{array}$} \\
\hline Left ventricular hypertrophy & $81(54 \%)$ & \\
\hline Left atrial hypertrophy & $48(32 \%)$ & $16(32.6 \%)$ \\
\hline Right ventricular hypertrophy & $6(4 \%)$ & $2(4 \%)$ \\
\hline Right atrial hypertrophy & $4(2.6 \%)$ & $2(4 \%)$ \\
\hline Atrial fibrillation & $49(32.6 \%)$ & $17(34.6 \%)$ \\
\hline Atrial flutter & $6(4 \%)$ & $3(6.1 \%)$ \\
\hline Supraventricular tachycardia & $2(1.3 \%)$ & $1(2 \%)$ \\
\hline Cardiac ischemia & $12(8 \%)$ & $8(16.3 \%)$ \\
\hline \multicolumn{2}{|c|}{ Echocardiographic data $(n=124)$} & Subject $>50$ years $(n=39)$ \\
\hline Left ventricular dilatation & $27(21.7 \%)$ & $7(17.9 \%)$ \\
\hline Left atrium dilation & $60(48.3 \%)$ & $12(30.6 \%)$ \\
\hline Right ventricular dilatation & $46(37.1 \%)$ & $14(35.8 \%)$ \\
\hline Right atrium dilation & $37(29.8 \%)$ & $14(35.8 \%)$ \\
\hline PAH between $35-50 \mathrm{mmHg}$ & $41(33 \%)$ & $9(23 \%)$ \\
\hline PAH between $50-60 \mathrm{mmHg}$ & $22(17.7 \%)$ & $9(23 \%)$ \\
\hline $\mathrm{PAH}>60 \mathrm{mmHg}$ & $8(6.4 \%)$ & $2(5.1 \%)$ \\
\hline Mitral valve insufficiency & $48(38.7 \%)$ & $11(28.2 \%)$ \\
\hline Tricuspid valve insufficiency & $42(33.8 \%)$ & $12(30.6 \%)$ \\
\hline Aortic valve insufficiency & $17(13.7 \%)$ & $4(10.2 \%)$ \\
\hline Pulmonary valve insufficiency & $2(1.6 \%)$ & $0(0 \%)$ \\
\hline left ventricular ejection impairment & $23(18.5 \%)$ & $7(17.9 \%)$ \\
\hline Pericardial effusion & $4(3.2 \%)$ & $2(5.1 \%)$ \\
\hline
\end{tabular}

Table 4. Analyze of patient's characteristics according pulmonary arterial hypertension (PAH), heart rhythm disorders and left ventricular ejection fraction (LVEF) impairment.

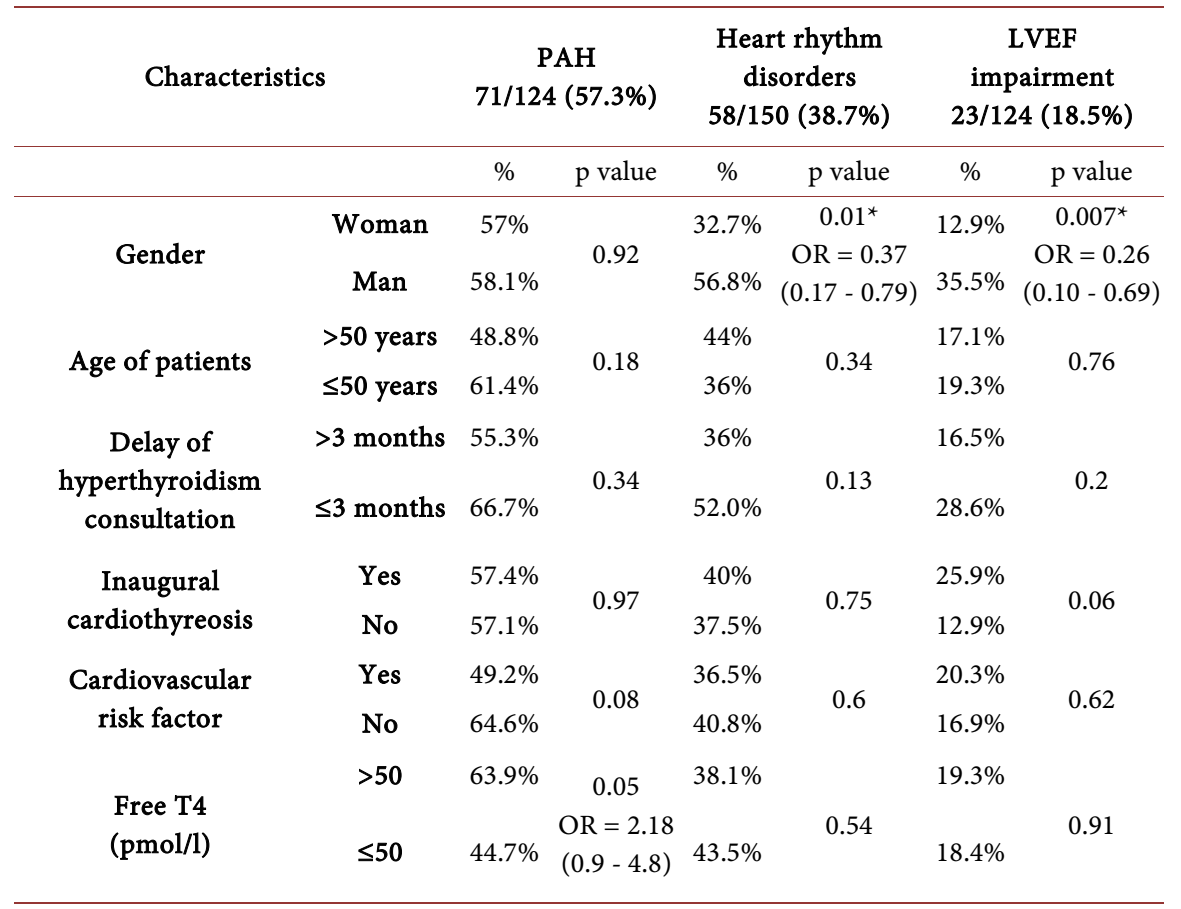

*: Statistically significant link. 
$47.5 \%$ valvular insufficiency.

Impaired of left ventricular ejection fraction was noted in $18.5 \%$. Of these patients, mean age, sex ratio and time limit onset of thyrotoxic heart disease were $41.3 \pm 17$ years, 0.9 and $24.8 \pm 37$ months respectively. Patients had arterial hypertension in $34.7 \%$, diabetes mellitus in $4.3 \%$ and their mean free T4 was 67.7 $\pm 35 \mathrm{pmol} / \mathrm{l}$. Among them, 34.7\% had heart rhythm disorders, $8.6 \%$ coronary insufficiency, $91.3 \%$ heart failure of stages III to IV of the New York Heart Association and $65.2 \%$ right heart failure. Female gender was statistically associated with the occurrence of a left ventricular ejection fraction impairment $(\mathrm{p}=$ 0.007). Moreover, there was no significant association between other patients' feature and the occurrence left ventricular ejection fraction impairment $(\mathrm{p}>$ 0.05).

Pulmonary arterial hypertension (PAH) was found in $57.3 \%$ of cases. Their mean age was $41.2 \pm 15$ years, sex ratio 0.34 , mean time to onset of thyrotoxic heart disease $32.5 \pm 44$ months, and mean free T4 level $78.3 \pm 73 \mathrm{pmol} / \mathrm{l}$. Arterial hypertension, heart rhythm disorders and coronary insufficiency were found in $26.7 \%, 38 \%$ and $5.6 \%$ respectively. Among patients with pulmonary arterial hypertension, $87.3 \%$ presented heart failure of stages III to IV of the New York Heart Association and 78.8\% right heart failure. Existence of a free T4 $>50$ $\mathrm{pmol} / \mathrm{L}(\mathrm{p}=0.05)$ was at risk for developing pulmonary arterial hypertension. Moreover, there was no significant association between other patients' characteristics and the occurrence of pulmonary arterial hypertension $(p>0.05)$. Nineteen patients (15.3\%) had an association with pulmonary arterial hypertension and impaired left ventricular ejection fraction.

\subsection{Evolution}

During the follow-up, 39 patients (26\%) were lost sight and 5 patients $(3.3 \%)$ had died in cardiology department. For the rest of 106 patients, a favorable evolution was found under heart specific treatment associated with the coverage of the thyrotoxicosis. The average duration of stabilization of the cardiac signs was of 6.9 months. Among 106 patients regularly followed, only 45 cases $(42.4 \%)$ were able to benefit from a thyroid surgical.

\section{Discussion}

Difficulties of this study are related to its retrospective nature and the high number of patients lost to follow-up. Besides all patients with a cardiothyreosis diagnosis were not able to benefit from a cardiac ultrasound.

This article is derived from a retrospective study conducted in a university hospital from patients' files. This kind of work doesn't require in Senegal the approval of ethic committee.

\subsection{Epidemiological Aspects}

Prevalence of cardiothyreosis seems to vary based on studies and sample size.

Our $9.8 \%$ seems to be lower than previous data in Africa. Frequency of $11.4 \%$, 
12.6\% and 16.6\% were reported in Mali [7], Congo Brazzaville [11] and Morocco [12] respectively. Yaméogo et al. [1] found a prevalence of 33.3\% among hyperthyroidism hospitalized in cardiology department. A prevalence of 3.3\% was reported by Tsymbaliuk et al. [13] in Ukraine in a series of 2221 cases of hyperthyroidism regardless to the cause. The female predominance is confirmed in all studies. Mean age of the patients was between 40 [7] [12] [14] and 50 years [1] [13]. In literature, thyrotoxic heart disease is associated with a number of cardiovascular factors such as hypertension, diabetes mellitus, underlying heart disease and anemia [1] [12] [13] [14]. These factors in our population were found in $31.3 \%, 6.6 \%, 10 \%$ and $24 \%$ respectively. Contrary to previous published data which reports a higher frequency of nodular goiter [7] [10] [12], Graves' disease was more common in our study.

\subsection{Clinical Study of Cardiothyreosis}

In the series of Kane et al. [14], time limit onset of cardiothyreosis was 24 months. It was $27 \pm 41$ months in our patients. The prevalence of $46.6 \%$ of thyrotoxic heart disease disclosing a hyperthyroid state is higher than $36 \%$ reported by Diallo et al. [7]. A higher prevalence of $79 \%$ in this condition is reported by Yaméogo et al. [1] in cardiology department. This should urge us to do more clinical investigations to detect the disease in uncomplicated early stages. Apart from subclinical forms, a thorough analysis of clinical findings allows us to establish an early diagnosis. Palpitations and tachycardia appear constantly in foreground of the clinical picture [7] [13] [14]. Heart failure of stage III/IV was found in $78.6 \%$ of our patients against $58.3 \%$ and $55.5 \%$ in series of Diallo et al. [7] in Mali and El Hattaoui et al. [12] in Morocco respectively. We report a higher prevalence of right heart failure followed by heart rhythm disorders. As part of an assessment of cardiothyreosis in patient with Graves' disease, Tsymbaliuk et al. [13] found a prevalence of heart failure in $69 \%$ and rhythm disorders in $72 \%$. In Morocco, El Hattaoui et al. [12] reported $66.6 \%$ and $75 \%$ for heart rhythm disorders and heart failure respectively.

\subsection{Electrocardiographic and Echocardiographic Study of Cardiothyreosis}

Various rate of cardiac wall involvement is reported in the literature. In our series, $62 \%$ of patients had heart chamber hypertrophy. A higher prevalence of $72 \%$ and $100 \%$ is found by Tsymbaliuk et al. [13] in Ukraine and Diallo et al. [7] in Mali respectively. In contrast to clinical finding which are suggestive of right heart involvement [7], electrocardiographic findings are more indicative of left heart involvement [15]. In a comparative prospective study between two Senegalese populations with and without cardiothyreosis, Kane et al. [14] reported a significantly higher left ventricular mass in population with thyrotoxic heart disease. In Burkina Faso, Yaméogo et al. [1] found a left ventricular hypertrophy in $85.7 \%$ of patients. In our series, in descending order, left ventricular, left atrial and finally right side involvement were more frequent. 
Atrial fibrillation is the most common rhythm and conduction disorder. A rate of $8 \%$ to $20 \%$ is reported [16] [17] [18]. Higher frequencies of $34 \%, 57.1 \%$, $66.6 \%$ and $72 \%$, are reported in Mali [7], Burkina Faso [1], Morocco [12] and Ukraine [13] respectively. Other electrocardiographic abnormalities were atrial flutter, and supra ventricular tachycardia. In our study, female gender is significantly associated with the occurrence of arrhythmias. Other factors mentioned in literature are age, underlying heart disease, heart failure and ischemic heart disease [16] [17] [18]. Only two of our patients had ischemic heart disease and heart rhythm disorder simultaneously. In other African series, coronary heart disease was associated with cardiothyreosis in 7.1\% [1], 11.1\% [12] and 28\% [7] of the patients.

Right chambers enlargement was the most frequent echocardiographic finding in our study. Data with a predominance of left chambers enlargement is reported by other authors in Africa [7] [12]. The thyrotoxic cardiomyopathy is a well-defined entity [10]. It occurs in $77 \%$ of Graves' disease with cardiothyreosis [13]. Its association with impaired left ventricular ejection faction is not uncommon. It was $26 \%$ and $33.3 \%$ in the series of Diallo et al. [7] in Mali and El Hattaoui et al. [12] in Morocco respectively. Sometimes multiple attacks are possible [12]. Our $18.5 \%$ of patients with left ventricular ejection faction impairment also had an arrhythmia (34.7\%), ischemic heart disease (8.6\%) and decompensate heart failure (65.2\%). Our study reports a significantly female risk of impaired left ventricular ejection faction $(\mathrm{p}=0.007)$. The prevalence of pulmonary artery hypertension seems to be the same with literature data. Suk et al. [19] reported a prevalence of $44 \%$ in a population with Graves' disease. However a lower prevalence $(21 \%)$ was found in another series of patients with Graves' disease [13].

\section{Conclusion}

Cardiothyreosis is a significant complication. It is dominated by rhythm disorders and right cardiac insufficiency. Echocardiographic abnormalities seem rather left in spite of a prevailing right clinical presentation. Female gender and severity of thyrotoxicosis seem to precipitate the clinical picture.

\section{Suggestion}

These discovery methods call for more early diagnosis and appropriate treatment. Echocardiography remains an indispensable tool for assessing cardiac consequences.

\section{Conflict of Interest}

The authors have nothing to disclose.

\section{References}

[1] Yaméogo, A.A., Yaméogo, N.V., Compaoré, Y.D., Ouédraogo, T.L. and Zabsonré, P. (2012) Cardiothyreosis at the University Hospital of Bobo-Dioulasso, Burkina 
Faso. The Pan African Medical Journal, 11, 1-7.

[2] Dahl, P., Danzi, S. and Klein, I. (2008) Thyrotoxic Cardiac Disease. Current Heart Failure Reports, 5, 170-176. https://doi.org/10.1007/s11897-008-0026-9

[3] Frost, L., Vestergaard, P. and Mosekilde, L. (2004) Hyperthyroidism and Risk of Atrial Fibrillation or Flutter: A Population-Based Study. Archives of Internal Medicine, 164, 1675-1678. https://doi.org/10.1001/archinte.164.15.1675

[4] Kahaly, G.J. and Dillmann, W.H. (2005) Thyroid Hormone Action in the Heart. Endocrine Reviews, 26, 704-728. https://doi.org/10.1210/er.2003-0033

[5] Niakara, A., Nébié, L.V.A. and Drabo, Y.J. (2000) Cardiothyreosis: Retrospective Study of 32 Cases in the Cardiology and Internal Medicine Department at Ouagadougou, Burkina Faso (1993-1998). Bulletin de la Société de pathologie exotique, 93, 25-28.

[6] Wade, B., Tiendrebeogo, A.J. and Charles, D. (1999) Cardiothyreosis: About 16 Senegalese Observations. Medicale d'Afrique Noire, 46, 251-257.

[7] Diallo, B., Sanogo, K.M., Diakité, S., Diarra, M.B. and Ba, S.S. (2004) The Cardiothyreosis at the G-Spot Hospital. Mali Medical, Tome XIX N², 22-27.

[8] Lorcy, Y. and Klein, M. (2005) Thyroid Dysfunction and Cardiovascular Disease: Encycl. Med. Chir, Cardiology, [11-048-A-10].

[9] Galiè, N., Torbicki, A., Barst, R., et al. (2004) The Task Force on Diagnosis and Treatment of Pulmonary Hypertension of the European Society of Cardiology. ESC guidelines: Guidelines on Diagnosis and Treatment of Pulmonary Arterial Hypertension. European Heart Journal, 25, 2243-2278.

https://doi.org/10.1016/j.ehj.2004.09.014

[10] Oliveros-Ruiz, L., Vallejo, M., Diez Canseco, L.F., Cárdenas, M. and Hermosillo, J.A.G. (2013) Determinants of Thyrotoxic Cardiomyopathy Recovery. BioMed Research International, 2013, Article ID: 452709. https://doi.org/10.1155/2013/452709

[11] Nkoua, J.L., Mban, B., Bandoho-Mambo, A., Aba, G. and Bouramoue, Ch. (2000) Cardiothyreosis: Frequency, Etiology and Nosology Aspect about 20 Cases. Medicale d'Afrique Noire, 47, 450-454.

[12] El Hattaoui, M., Charei, N., Mouniri, M. and Diouri, A. (2009) Cardiothyreosis in the Region of Marrakesh: about 36 Cases. Ann Cardiol Angeiol, 58, 135-138. https://doi.org/10.1016/j.ancard.2008.07.006

[13] Tsymbaliuk, I., Unukovych, D., Shvets, N. and Dinets, A. (2015) Cardiovascular Complications Secondary to Graves' Disease: A Prospective Study from Ukraine. PLoS One, 10, 1-15. https://doi.org/10.1371/journal.pone.0122388

[14] Kane, A., Fall, M.D., Diop, I.B., Hane, L., Sarr, M., Ba, S.A. and Diouf, S.M. (1998) Echocardiographic Parameters in Hyperthyroidism with and without Cardiothyreosis. Ann Endocrinol, 59, 14-19.

[15] Anakwue, R.C., Onwubere, B.J., Ikeh, V., Anisiuba, B., Ike, S. and Anakwue, A.M.C. (2015) Echocardiographic Assessment of Left Ventricular Function in Thyrotoxicosis and Implications for the Therapeutics of Thyrotoxic Cardiac Disease. Therapeutics and Clinical Risk Management, 11, 189-200. https://doi.org/10.2147/TCRM.S68752

[16] Petersen, P. and Hansen, J.M. (1988) Stroke in Thyrotoxicosis with Atrial Fibrillation. Stroke, 19, 15-18. https://doi.org/10.1161/01.STR.19.1.15

[17] Frost, L., Vestergaard, P. and Mosekilde, L. (2004) Hyperthyroidism and Risk of Atrial Fibrillation or Flutter: a Population-Based Study. Archives of Internal Medicine, 164, 1675-1678. https://doi.org/10.1001/archinte.164.15.1675 
[18] Traube, E. and Coplan, N.L. (2011) Embolic Risk in Atrial Fibrillation that Arises from Hyperthyroidism: Review of the Medical Literature. Texas Heart Institute Journal, 38, 225-228.

[19] Suk, J.H., Cho, K.I., Lee, S.H., et al. (2011) Prevalence of Echocardiographic Criteria for the Diagnosis of Pulmonary Hypertension in Patients with Grave's Disease: Before and after Anti-Thyroid Treatment. Journal of Endocrinological Investigation, 34, 229-234.

Submit or recommend next manuscript to SCIRP and we will provide best service for you:

Accepting pre-submission inquiries through Email, Facebook, LinkedIn, Twitter, etc. A wide selection of journals (inclusive of 9 subjects, more than 200 journals) Providing 24-hour high-quality service User-friendly online submission system Fair and swift peer-review system Efficient typesetting and proofreading procedure Display of the result of downloads and visits, as well as the number of cited articles Maximum dissemination of your research work

Submit your manuscript at: http://papersubmission.scirp.org/ Or contact ojim@scirp.org 